\title{
El lugar de Hume en una posible historia natural de las teorías políticas
}

\section{Hume's Place in a Hypothetical Natural History of Political Theories}

\author{
Carmen Ors Marqués ${ }^{1}$ \\ Universidad de Valencia (España)
}

Recibido: 14-05-18

Aprobado: 19-06-18

\section{Resumen}

En su obra Historia natural de la religión, David Hume narra la historia de las religiones intentando encontrar sus causas psicológicas y sociales. El presente escrito intenta aplicar esta metodología humeana a su propia teoría política, señalando su significado político y cultural. El resultado es considerar a Hume un pensador realista que combina la historia y la filosofía con el objetivo de moderar las pasiones frente a la superstición y el entusiasmo, de forma que la organización de la sociedad sea de acuerdo al principio de utilidad (justicia). En suma, podemos ver en él un profeta de un nuevo mundo feliz: el protocapitalista y burgués.

Palabras-clave: teorías políticas, religión, superstición, entusiasmo, justicia, utilidad, surgimiento del capitalismo.

\footnotetext{
${ }^{1}$ (carmenorsmarques@gmail.com). Profesora de educación Secundaria del IES Barri del Carme (Valencia). Ha realizado su tesis doctoral en la Universidad de Valencia con el título "Razón y cultura en la filosofía de Ernest Gellner". Ha compaginado su estudio en filosofía con la labor de traducción, por ejemplo, Hume, D. (2004): Investigación sobre el entendimiento humano. Edición bilingüe. Traducción de Vicente Sanfélix Vidarte y Carmen Ors Marqués. Líneas de investigación: tradición epistemológica moderna, nacionalismo y modernidad, filosofía y cine. Publicaciones: Ors C. "Empirismo y sociedad: una lectura gellneriana de Hume" en Gerardo López Sastre (ed.), David Hume: Nuevas perspectivas sobre su obra. Ediciones de la Universidad de Castilla-la Mancha. pp. 147-165 (2005); Ors, C., Sanfelix, V., (2013): “¿Por qué luchamos ¿La antropología política del documental norteamericano de propaganda bélica" en Ekasia, Revista de filosofia; Ors, C., Sanfelix, V.,(2014): Esprit Detaché. El yo en las meditaciones, Valencia, Pretextos; Ors, C.,(2016): "Identidad/ es. Una reflexión sobre la identidad de la mujer en el cine de Icíar Bollaín y Gracia Querejeta" en Daimon. Revista Internacional de Filosofia. Suplemento 5.
} 


\begin{abstract}
In his work The Natural History of Religion, David Hume writes about the history of religions trying to find their psychological and social causes. This paper tries to apply this Humean methodology to his own political theory, pointing out its cultural and social meaning. I maintain that Hume is a realistic thinker that combines history and philosophy in order to moderate the passions that are dominant in superstition and enthusiasm. In this way he tries to organize society according to the principle of utility (justice). So we can see in him the prophet of a new brave world: the protocapitalist and bourgeois.
\end{abstract}

Key-words: political theories, religion, superstition, enthusiasm, justice, utility, rising of capitalism.

\title{
1. ¿Es posible teorizar la política desde un punto de vista naturalista?
}

La Historia natural de la religión escrita por Hume en 1751 formaría parte de su proyecto de una ciencia de la naturaleza humana, se puede afirmar incluso que es un capítulo particular de la misma. Explicar la religión desde un punto de vista naturalista, distanciado, supone adoptar lo que en antropología se conoce como un punto de vista etic, el del observador externo y no participante. Este libro de Hume, en terminología contemporánea, en vez de "historia natural" podría etiquetarse como una antropología o sociología de la religión en tanto que intenta explicar la variedad de creencias y experiencias religiosas y su evolución a partir de ciertas disposiciones mentales de los seres humanos en determinados contextos sociales e históricos. Se podría utilizar esta metodología de Hume para aplicarla a las teorías políticas, establecer un paralelismo y emular a nuestro autor, adoptar un punto de vista distanciado (etic) para comprender el papel que han jugado y juegan las teorías políticas, preguntarnos qué interés o disposición mental subyace en el esfuerzo de conceptualización de lo político, y cómo este correlaciona con un determinado marco social, para después señalar el lugar de Hume en esta empresa.

Evidentemente, se podría objetar que no es lo mismo profesar una fe o practicar una religión que teorizar, no es lo mismo ser un teólogo católico que ir a comulgar, por poner un ejemplo; en todo caso el paralelismo sería válido si de lo que tratásemos fuera de evaluar las ideologías políticas y las prácticas que acarrean. No obstante, aceptando lo burdo del paralelismo lo que buscamos es esa mirada naturalista que practicó el filósofo escocés, esa actitud distanciada que tanta afinidad electiva guarda con la actitud escéptica de la que hacía gala.

Pero antes de comenzar ya surgen una serie de interrogantes, ¿acaso es 
posible la actitud distante, "naturalista" como Hume la llama, a la hora de teorizar sobre religión o política?, ¿no es cierto que cuando Hume escribió sobre religión, aunque se esforzara, perseguía ciertos intereses de índole práctica?, ¿y que ese interés también se puede trasladar al que teoriza sobre política?

Centrándonos de momento en la religión, tendremos que reconocer que el distanciamiento al intentar explicar la cuestión religiosa es difícil, y señalar que más bien lo que intenta Hume es explicar la religión desde lo humano; ese puede ser el verdadero sentido del adjetivo "natural", el del punto de vista inmanente, es decir: humano. Además, otra razón importante es que el análisis de Hume de la religión está íntimamente conectado con su filosofía política. Sus análisis recurrentes de la religión a lo largo de su obra tendrían como objetivo general desgajar la política y la moral de cualquier metafísica religiosa y, si hilamos más fino, algunos textos apuntarían a problemas más coyunturales, concretamente a desenmascarar ciertos puntos de vista sobre la sociedad y la política predominantes todavía en sus días que hundirían sus raíces en las dos formas degeneradas (pues Hume siempre habla, otra cosa es si lo hace retóricamente, de una verdadera religión) de religión que Hume tipifica: la superstición y el entusiasmo.

La respuesta que podemos dar al interrogante que daba título a este epígrafe es, por lo tanto, negativa. Es difícil, por no decir imposible, adoptar un punto de vista naturalista, en el sentido de neutral o distanciado, tanto ante la religión como ante la política, dos terrenos que además en el análisis de nuestro autor, como veremos, se han condicionado históricamente. De ahí que el punto de vista que voy a defender es que los escritos de Hume son acciones o formas de hacer política, como en general cualquier conceptualización de la política y lo político. Las teorías políticas contribuyen a remodelar las opiniones a través del esfuerzo de conceptualización, los conceptos que generan implican prácticas que a su vez modelan la política y la sociedad. Hume tenía muy claro estos diferentes niveles en los que operan los saberes y cómo resultan de utilidad unos con respecto a otros ${ }^{2}$.

Pensemos un poco en el proyecto de Hume tal y como lo plantea en dos de sus principales obras: el Tratado de la naturaleza humana y La investigación sobre el entendimiento humano En esta última, reelaboración más cuidada

\footnotetext{
2 "Y aunque el filósofo pueda vivir apartado de los negocios, el espíritu de la filosofía, si es cuidadosamente cultivado por unos cuantos, debe difundirse gradualmente a través del conjunto de la sociedad, y aportar a todo arte y oficio una precisión análoga. El político ganará una mayor previsión y sutileza al dividir y equilibrar el poder; el abogado, más método y más finos principios en sus razonamientos; y en general, más regularidad en su disciplina y más cautela en sus planes y operaciones. La estabilidad de los modernos gobiernos, por comparación con los antiguos, y el rigor de la filosofía moderna han mejorado, y probablemente aun mejorarán, en la misma medida". Hume, D. (2004): Investigación sobre el entendimiento humano, Sec. I. 9, Sobre las diferentes especies de filosofía, Madrid, Ediciones Istmo. Edición bilingüe. Traducción de Vicente Sanfélix Vidarte y Carmen Ors Marqués. Introducción, notas y comentarios de Vicente Sanfélix Vidarte. Epílogo de Barry Stroud.
} 
del Libro I del Tratado, se establece la equivalencia entre filosofía moral y ciencia de la naturaleza humana. Con esta disciplina Hume está hablándonos de un proyecto que hoy, más de dos siglos y medio después, conocemos como ciencias sociales y humanas. $\mathrm{Su}$ proyecto incluye además una metafísica o filosofía moral abstrusa, desarrollada para calibrar los poderes y facultades de la mente, i. e. como fundamento y límite de los saberes que con posterioridad se desarrollarían o consolidarían como ciencias sociales y humanas: política, economía, sociología, historia, antropología y un largo etcétera, saberes a los que Hume contribuyó con su gran curiosidad y dedicación intelectual. Hume se esfuerza por aclararnos los diferentes niveles de discurso que suponen la metafísica o filosofía moral abstrusa o lógica como le llama en el Compendio y el resto de áreas de la ciencia de la naturaleza humana ${ }^{3}$. Desde mi punto de vista la posición de Hume podría resumirse invirtiendo la famosa frase kantiana y decir algo así como: poner límites a la fe para dar paso al conocimiento.

\section{El naturalista clasifica}

Pero volvamos a la intención original: imaginar a la manera humeana una historia natural de la política y pensar el lugar de Hume en ella. Aunque desde mi punto de vista quien escribe sobre política no lo hace con un mero interés descriptivo, concederé que cierta reflexividad y distancia es posible. Y esa "especie" de filosofía o saber que Hume llama "historia natural" requiere una buena atalaya a la que encaramarse. Del mismo modo que Hume se propone averiguar cuáles son las causas psicológicas o sociales que están a la base de las creencias religiosas con independencia de la justificación racional de las mismas, podemos proponernos aventurar una hipótesis ${ }^{4}$ sobre el interés o el origen de una teoría política.

Dado que sería vano, por imposible en estas páginas, trazar toda una historia de las teorías políticas, rizando el rizo podemos seguir a Hume de nuevo y utilizar la distinción entre superstición y entusiasmo ${ }^{5}$ para intentar establecer los principios que engendran el interés ${ }^{6}$ por teorizar sobre la política.

\footnotetext{
${ }^{3}$ Cf. Hume, D., (2004): Sec I, "De las diferentes especies de filosofía".

${ }^{4}$ Hume se habría encargado de argumentar en contra de la justificación racional de algunas creencias fundamentales en las que se sustenta la religión revelada, por ejemplo, en los Diálogos, Hume, D, (1993): Dilogues and Natural History of Religion. Ed. J. C. A. Gaskin, Oxford, Oxford University Press; o en la misma Investigación sobre el entendimiento humano, Hume, D., (2004): Sec. 10 y 11.

5 "De la superstición y el entusiasmo" en Hume, D. (2011): Ensayos morales, políticos y literarios. Madrid, Editorial Trotta y Liberty Fund. Edición, prólogo y notas de Eugene F. Miller. Traducción de Carlos Martín Ramírez, p. 100.

${ }^{6}$ En estos términos parece planteárselo: "What those principles are, which give rise to the original belief, and what those accidents and causes are, which directs its operations, is the subject of our present enquiry", Cf. Hume, D. (1993).
} 
En el breve ensayo donde Hume introduce esta distinción nos habla de que ante los asuntos públicos y privados la reacción de los seres humanos es diferente en función del talante, las circunstancias sociales o personales, o la personalidad de los individuos. Unos reaccionarán con miedo, que unido a la ignorancia es el caldo de cultivo adecuado para la superstición; por oposición, hay otro tipo de personas cuyo ánimo y circunstancias les predisponen al orgullo y la fantasía, estos últimos son los entusiastas. Estas dos formas de corrupción de lo mejor que engendra lo peor, o expresiones de lo demasiado humano, correlacionan con puntos de vista sobre la política y sobre la sociedad. La conclusión es bien conocida: la superstición, debido a que hunde sus raíces en el miedo casa bien con la aceptación de la autoridad y el gobierno despótico; el entusiasmo correlaciona más con el autogobierno y a largo plazo, subrayemos esto último, con la tolerancia; es decir, nos encontramos dos actitudes antagónicas ante lo privado y lo público que generan dos visiones opuestas de uno de los valores clave de lo que tradicionalmente se ha considerado el bien común de la política: la libertad.

Tenemos que dejar bien claro que estamos forzando la distinción de Hume entre superstición y entusiasmo. Está claro que en el ensayo mencionado Hume define estas especies de falsa creencia como corrupciones de la religión, estableciendo que hay una política propia de determinada religión ${ }^{7}$. Pero no tenemos por qué pensar en esas dos actitudes extremas ni coyunturales al periodo histórico en el que Hume está reflexionando, sino en las pasiones que las engendran, pues quizás estén en la raíz del que emprende la teorización de lo político. Podríamos aventurar la hipótesis de que el interés por teorizar lo político está vinculado normalmente a pasiones de signo opuesto: el miedo al cambio social o, por el contrario, la fantasía y el orgullo, buenos revulsivos o catalizadores para provocar el cambio social. Respaldar el orden establecido, dotarlo de un relato que lo legitime o, por el contrario, buscar con entusiasmo su disolución, imaginando una alternativa, pueden ser los intereses que subyacen a pensar lo político. Conservadores o revolucionarios y entre estos dos extremos, reformistas. Esta es, si se nos permite, la clasificación que extraemos de las dos motivaciones que para Hume están por detrás de la exacerbación de las creencias religiosas que como plantea Hume correlacionan con maneras de concebir la política. Clasificación que, para cerrar el círculo, aplicaremos al pensamiento político del mismo Hume.

\footnotetext{
${ }^{7}$ En esta línea argumenta Haakonssen, K. en "The structure of Hume's polítical theory” en Norton, D. F. (ed.) (1993): The Cambridge Companion to Hume. Cambridge: Cambridge University Press.
} 


\section{Situando al pensamiento político de Hume}

Comenzaremos este apartado recapitulando. En esta historia natural imaginaria de la filosofía política hemos introducido una clasificación según la cual las teorías políticas no se formulan con un simple interés teórico, sino que se plantean como instrumentos al servicio de una praxis, es decir, o bien para respaldar un orden ya establecido que se pretende legitimar o bien para posibilitar el cambio social. De forma que podemos proponer tres tipos ideales: las del primer tipo serían las teorías conservadoras, mientras que las del segundo serían revolucionarias, y habría un tercero, más moderado, que busca un cambio social gradual, llamémosle reformistas. Lo que hemos añadido inspirándonos en el Hume sociólogo de la religión es una idea harto discutible, una idea por la que se nos puede acusar de psicologismo, a saber: que una teoría política de corte conservador deriva de ciertos rasgos del carácter o disposiciones mentales quizás influenciadas por las circunstancias, concretamente del miedo; mientras que la revolucionaría derivaría respectivamente de pasiones como el orgullo mezclado con la imaginación. Si al menos nos hubiéramos limitado a quedarnos en el nivel de las ideologías, seguro que nuestra hipótesis podría ser menos descabellada; parece natural que las personas temerosas no estén abiertas a apreciar los cambios, cuanto menos por aquello del más vale malo conocido, pero ¿es extrapolable al plano de la teoría? Para evitar esta objeción podríamos aventurarnos a conjeturar que no necesariamente tenemos que actuar cual psicólogos de la sospecha y atribuir la teorización a cierta pasión rectora sea el miedo o el orgullo, característica de la personalidad de los filósofos políticos, sino que estos últimos, conocedores de la naturaleza humana, saben de estos resortes como fundamento de la esencia de lo político. Es decir, que es el miedo y el orgullo lo que está a la base de las lealtades políticas. ¿Puede haber otras pasiones más moderadas?

La respuesta a esta última pregunta nos llevará a plantearnos cómo situar a Hume ipretende su teoría respaldar un orden o por el contrario ser un instrumento al servicio del cambio social?, ¿es la teoría política de Hume esclava de sus pasiones?, ¿de qué tipo de pasiones? Una de las dificultades que implica abordar el pensamiento político de Hume es, como bien han planteado algunos comentaristas, percatarse de la doble naturaleza de su pensamiento social y político, un pensamiento que aúna el punto de vista del filósofo y el punto de vista del historiador, y la estrecha conexión ${ }^{8}$ y complementariedad entre ambos. Lo que el Hume historiador de la religión subraya es algo que la tradición filosófica ha puesto de manifiesto: su papel instrumental en el mantenimiento, respaldo y legitimidad de los gobernantes. Las religiones están a la base de los proyectos políticos y de sus puestas en marcha, en un

\footnotetext{
${ }^{8}$ Cf. por ejemplo Haakonssen, K., op. cit., p. 183.
} 
movimiento de retroalimentación, y estos procesos han sido implementados las más de las veces a sangre y fuego, y no a través de una conversión voluntaria.

Ernest Gellner ${ }^{9}$ encuentra una tensión que le parece fascinante en la filosofía de la religión de Hume. Según él, Hume defiende en la Historia natural de la religión que la superstición se corresponde con el tipo de creencias y prácticas propias de la religión clásica, dando lugar a una religión social, cívica, terrenal, comunal, tradicional y tolerante, mientras que el entusiasmo sería egoísta, espiritualista, doctrinario e intolerante. La tensión o contradicción estriba en que, aunque el catolicismo correlaciona con la superstición y el protestantismo con el entusiasmo, Hume se da cuenta de que en donde se impone el protestantismo acaban floreciendo regímenes más tolerantes que defienden la libertad civil, tesis como hemos visto vertida en "De la superstición y el entusiasmo".

¿Cómo superar esta contradicción en el pensamiento de Hume? La respuesta de Gellner que queremos suscribir es convertir a Hume en un weberiano avant la lettre: el breve ensayo de Hume merecía contarse como una contribución al debate sobre el papel del protestantismo en el surgimiento de la modernidad y el capitalismo o mercantilismo (protocapitalismo). Los hechos son los que apoyan esta hipótesis: según relata Hume, aunque el entusiasmo, dado que reivindica una fe seria y sin concesiones, correlaciona con la intolerancia, ya que no permite, por así decirlo, ningún aditamento sincrético, sin embargo, puede contribuir a la libertad. La principal de las razones que explicarían este hecho es que elimina el sacerdocio como casta separada al universalizarlo, lo que trae importantes consecuencias, pues al no haber una clase de hombres que mantengan la llama de la fe, esta con el tiempo se debilita, volviendo a los practicantes más tolerantes. En cierto modo esta es la tesis weberiana de la rutinización.

Con esta premisa vamos a avanzar la que será nuestra tesis en esta especie de fabulación sobre la historia natural de las teorías políticas. Desde de mi punto de vista la teoría política de Hume es una teoría pionera, porque está ayudando a dar luz al nuevo orden social que se está gestando. Cuando me preguntaba qué tipo de interés subyace al pensamiento político de Hume, y si su teoría política es esclava de sus pasiones, la respuesta que me parece más plausible es que Hume, desde el realismo propio del que sintetiza dos puntos de vista: el del historiador y el del filósofo, estaría contribuyendo a codificar el orden social de la sociedad capitalista burguesa emergente, y su objetivo es subordinar la política a pasiones moderadas. Hume es un espíritu tranquilo, su pensamiento político está al servicio del cambio social que se está gestando en su tiempo pero desde luego no pretende ni revoluciones, ni grandes choques sociales.

\footnotetext{
${ }^{9}$ Gellner, E. (1996): Condiciones de la libertad. La sociedad civil y sus rivales. p. 47-49. Barcelona, Paidós.
}

Araucaria. Revista Iberoamericana de Filosofia, Politica, Humanidades y Relaciones Internacionales, año 20, ${ }^{\circ} 40$. Segundo semestre de 2018. Pp. 333-347. ISSN 1575-6823 e-ISSN 2340-2199 doi: 10.12795/araucaria.2018.i40.15 
Para entender esa doble faceta de historiador y filósofo y cómo sus teorías fueron catalizadoras del cambio social utilizaré la distinción contemporánea entre visión asociativa y disociativa de la política ${ }^{10}$. Desde un punto de vista disociativo, lo político es un espacio de poder y de conflicto, de oposición. ¿Cuál es el enemigo al que se opone la política humeana? Ya lo he apuntado: el enemigo es, por un lado, toda política que se base en una metafísica religiosa, pero, por otro, también recelará de las teorías contractualistas que se remontan a un contrato originario y que hablan de leyes o derechos naturales ${ }^{11}$. Estas filosofías políticas como muestra el ensayo que acabamos de citar, Del contrato original, eran utilizadas respectivamente por Tories y Whigs como principios y fundamentos en los que basar la lealtad al gobierno.

La principal crítica de Hume a la teoría del contrato original como elemento de respaldo o de lealtad es su flagrante circularidad:

"Si se me pregunta por la razón de la obediencia que hemos de prestar al gobierno, me apresuraré a contestar: porque de otro modo no podría subsistir la sociedad; y esta respuesta es clara e inteligible para todos. La vuestra seria: porque debemos mantener nuestra palabra. Pero, aparte de que nadie no educado en un cierto sistema filosófico puede comprender o encontrar de su gusto esta respuesta, os veréis en un apuro si os pregunto a mi vez: ¿por qué hemos de mantener nuestra palabra?; y no podréis dar otra respuesta que la que habría bastado para explicar de modo inmediato, sin circunloquios, nuestra obligación de obedecer"12.

En suma, que Hume se aleja de los principales relatos que utilizan los partidos de su tiempo como elemento legitimador, y al alejarse de esos relatos también está intentando que la lealtad al gobierno se base en unos principios psicológicos diferentes al miedo y al orgullo. Si el común de los mortales, a la postre, basa su lealtad al gobierno en algún tipo de sentimiento o afección, mejor que sea por pasiones moderadas y no fanáticas.

\section{Liberalismo minimalista: in media res}

Pero dejemos de lado la lógica amigo-enemigo, olvidemos a quién combate la filosofía política humeana y pasemos a señalar cómo su teoría es la codificación de un incipiente orden protocapitalista y burgués. Vamos ahora a centrarnos en la otra manera de abordar la política, la visión asociativa, Hume expone con sencillez en el Compendio el objeto o fin de la política: esta "considera a los hombres reunidos en sociedad y dependientes los unos

\footnotetext{
10 Distinción que se deriva de la obra de Carl Schmitt, Smichtt, C. (1999): El concepto de lo político, Alianza Editorial, Madrid.

11 “Del contrato original" en Hume, D. (1987): Ensayos politicos, Madrid, Tecnos.

12 Ídem p. 110-111.
} 
de los otros"13. ¿Qué es lo que hace a los hombres dependientes entre sí para necesitar estructuras o instituciones políticas? ¿Cómo articular las conductas individuales en un proyecto general u orden?, ¿cuál debería ser la principal finalidad de ese orden?, ¿qué emociones o pasiones deberían llevar a los seres humanos a respetar el orden político? La respuesta a estas preguntas revelará el lugar que hemos otorgado a la filosofía política del filósofo escocés.

Lo primero sobre lo que quiero insistir es en que la doble naturaleza, histórica y filosófica, de las reflexiones políticas de Hume le llevan al realismo; su teoría política ni se plantea un modelo utópico al que tender, ni una situación hipotética de la que deducir unas leyes naturales que fundamenten las reglas de la justicia; como buen empirista debe no fingir hipótesis. Por otra parte, su teoría es bastante minimalista, no comienza por ofrecer lo que todo el mundo esperaría de una teoría política: la explicación de la forma del gobierno y de quién tiene la legitimidad para ejercerlo, a fin de cuentas, de lo que se trata es de describir la naturaleza humana. Su planteamiento comenzará in media res, no imaginando seres asociales, sino describiendo aquellas cualidades de los seres humanos que son las más adecuadas para la vida social ${ }^{14}$ y su fundamento en determinado de tipo sentimiento que es constitutivo de la naturaleza humana, la simpatía. De esta forma en el Libro III, II Parte, del Tratado, se transita de la moral a la política, de lo que Hume considera virtudes "naturales" a una virtud artificial que recibe el nombre de justicia; bien es verdad que se da cuenta de la polisemia del término "natural" y discute los diferentes significados que podemos atribuirle, puesto que en cierta manera no hay significados morales inherentes a la naturaleza de las $\operatorname{cosas}^{15}$.

La sociabilidad brota por tanto de nuestra naturaleza, su traducción en actos se concretará gracias a ciertos "principios estables de la mente, que se extienden por toda la conducta y forman parte del carácter personal"16, el criterio para considerar esas cualidades o propensiones como virtuosas es lo útil, lo placentero o agradable ${ }^{17}$ para nosotros mismos y/o para los demás. Estas

13 Hume, D. (1977): Compendio de un tratado de la naturaleza humana. Versión castellana de Carmen García Trevijano y Antonio Garcia Artal. Valencia, Teorema.

14 “(...) la mayoría de las cualidades a las que damos naturalmente nuestra aprobación tienen efectivamente esa tendencia (el bien de la humanidad) y convierten al hombre en un digno miembro de la sociedad, mientras que las cualidades naturalmente censuradas muestran la tendencia contraria y hacen que cualquier relación con esa persona sea peligrosa y desagradable" Hume, D. (1988) p. 824.

${ }^{15}$ Ídem, p. 694.

${ }_{16}$ Ídem, p.820.

17 "Parece que nunca hubo una cualidad que alguien recomendara como una virtud o excelencia moral sino en razón de resultar útil o agradable al mismo hombre o a otros. Porque ¿qué otra razón puede darse para el elogio o la aprobación? O ¿qué sentido tendría ensalzar un buen carácter o una buena acción que al mismo tiempo se admite que no son buenas para nada? Por lo tanto, todas las diferencias en la moral pueden reducirse a un único fundamento general y se las puede explicar por los diferentes puntos de vista que la gente tiene de estas circunstancias." Hume, D. (1991), Un diálogo, en Investigación sobre los principios de la moral. Edición y traducción de Gerardo López Sastre, Espasa-Calpe, Madrid, p. 215.

Araucaria. Revista Iberoamericana de Filosofia, Política, Humanidades y Relaciones Internacionales, año 20, ${ }^{\circ} 40$. Segundo semestre de 2018. Pp. 333-347. ISSN 1575-6823 e-ISSN 2340-2199 doi: 10.12795/araucaria.2018.i40.15 
cualidades, que Hume califica como virtudes naturales, son el pegamento de la vida social; por ejemplo, generosidad, compasión, conocimiento, amabilidad, por enumerar algunos ejemplos. Para Hume son "naturales" en la medida en que las acciones que derivan de ellas establecen relaciones entre agentes y pacientes particulares, dicho de otro modo, tienen que ver con las relaciones cara a cara, relaciones auto-contenidas y completas. ¿Da cuenta esta sociabilidad natural de las relaciones políticas? La respuesta de Hume es negativa, por ellas mismas no son suficientes para implementar el complejo orden de la vida en sociedad, esta necesita de otros artificios y convenciones, exige que se generen en los seres humanos ciertas prácticas que no surgen espontáneamente de su sociabilidad natural, sino que han devenido históricamente sea por azar, previsión o cálculo y por el comportamiento imitativo. Estas prácticas en las que se establecen relaciones de lealtad y obligación, con terceros que no tenemos por qué conocer ni tampoco tienen por qué merecer nuestra obligación, se engloban en el término genérico "justicia" y, en general, tienen que ver con obligaciones sociales, por una parte, y contratos que se derivan de las relaciones de propiedad, por otra. Estas prácticas, en tanto que históricamente devenidas también pueden ser históricamente modificadas; son contingentes, podrían ser de otra manera y tienen un interés práctico, se fundamentan como el resto de virtudes en la utilidad. Frente al orgullo o el miedo, la lealtad a las instituciones políticas tiene que tener que ver con la utilidad.

En este punto discrepamos de la interpretación que hace Martha Nussbaum del significado político de la teoría de la justicia de Hume. Esta autora, quizás se deja confundir por el orden de la investigación del Libro III, II Parte, del Tratado, que va de las virtudes naturales a la virtud artificial de la justicia, pensando que es posible el desarrollo de las virtudes naturales sin el artificio de la justicia; dice Nussbaum:

"El arte de la política sería una herramienta al servicio de una finalidad ya constituida. He aquí la explicación dada por Hume del origen y la finalidad de la justicia. La justicia figura como una "virtud artificial" que sirve a los objetos separados de ella; solo es natural en cuanto medio necesario para la consecución de las metas naturales y en cuanto que corresponde a la naturaleza humana idear los medios para alcanzar dichas metas. En otras palabras, podemos imaginar una vida realmente humana carente de justicia y de instituciones políticas. Estaría llena de dificultades y peligros, pero seguiría siendo reconocible para nosotros y englobaría todos nuestros fines naturales. Quienes la vivieran serían miembros de nuestra gran comunidad humana y reconoceríamos en ella una naturaleza común en nosotros. En resumen, el ser humano no sería una criatura política por naturaleza"18.

\footnotetext{
${ }^{18}$ Nussbaum, M. C. (2015) La fragilidad del bien. Fortuna y ética en la tragedia y en la filosofia griega. Madrid. Antonio Machado Libros, p. 152.
}

Araucaria. Revista Iberoamericana de Filosofía, Política, Humanidades y Relaciones Internacionales, año 20, $\mathrm{n}^{\circ} 40$ Segundo semestre de 2018. Pp. 333-347. ISSN 1575-6823 e-ISSN 2340-2199 doi: 10.12795/araucaria.2018.i40.15 
¿Corresponde esta descripción a una vida en estado de naturaleza ("carente de justicia e instituciones políticas", con el sentido profundo de las relaciones individuo y sociedad tal como las entiende Hume? ¿Sería posible según Hume, como le atribuye Martha Nussbaum, desarrollar una gran comunidad humana sin los "artificios" de la justicia? Desde mi punto de vista esa "arcadia" que describe Nussbaum está lejos de los planteamientos humeanos. No sabemos hasta qué punto una amplia comunidad humana podría vivir y más aún vivir bien sin esa estructura política, "un bien común u orden", llámese justicia e impleméntese como se considere, en el caso de Hume: como relaciones sociales y relaciones que se derivan de la propiedad.

Lo que sí que es cierto es que lo político no tiene autonomía, lo político se subordina a lo social y lo económico. Hume explica la necesidad de lo político en términos economicistas, la sociedad se explica, por una parte, ante la escasez de bienes en relación a las necesidades y deseos y, por otro, por el egoísmo moderado, lo cual ya nos pone sobre la pista de que la justicia tiene que ver con la distribución de los bienes, fundamentalmente. ¿Es posible una amplia comunidad humana solo basadas en las virtudes naturales? Si fuera así sería todo menos amplia, pues se reduciría a círculos bastante íntimos, a relaciones cara a cara. Hume plantea que es imposible mantener una sociedad sin justicia y sin la observancia de las tres leyes fundamentales relativas a la estabilidad de las posesiones, la transferencia por consentimiento y el cumplimiento de las promesas. Estas leyes son anteriores al gobierno y las instituciones políticas e imponen una obligación independiente, ahora bien, no son leyes naturales al modo en que se entendía este tipo de principios por el iusnaturalismo, son prácticas.

Hume explica la lealtad a las reglas de la justicia de nuevo en términos de utilidad: vivir en sociedad y cumplir estas reglas tiene ventajas cooperativas (aumento de poder y habilidad, mayor seguridad); no obstante, cada acto de lealtad que presuponga las reglas de la justicia no tiene por qué explicarse por un cálculo, decisión o deliberación, ni por un acuerdo explícito sino más bien como la asunción de roles, una especie de contrato implícito, recordemos el famoso símil de bote de remos: lo remeros actúan de consuno "en virtud de un acuerdo o convención, a pesar de que nunca se hayan prometido nada mutuamente"19, así funcionan la mayor parte de las relaciones sociales y de intercambio. Nuestro autor da un paso importante pues para explicar cómo surgen las convenciones sociales básicas, es en cierto modo la idea weberiana de la rutinización, un elemento fundamental para entender y dinamizar el cambio social. Pero, aunque las reglas de la justicia se puedan seguir por simple concordancia en las prácticas, también es cierto que podemos experimentar un sentimiento de moralidad, llamémosle satisfacción moral, en el cumplimiento de las mismas.

\footnotetext{
${ }^{19}$ Hume, D. (1984): p.715.
}

Araucaria. Revista Iberoamericana de Filosofia, Política, Humanidades y Relaciones Internacionales, año 20, ${ }^{\circ} 40$. Segundo semestre de 2018. Pp. 333-347. ISSN 1575-6823 e-ISSN 2340-2199 doi: 10.12795/araucaria.2018.i40.15 
La sociedad descrita desde los incentivos anteriores parece algo así como una aventura colaborativa; ahora bien, Hume también va a introducir un elemento competitivo. Elemento que se precisa cuando se enfrenta a explicar la legitimidad de la propiedad y los mecanismos que garantizan su estabilidad, así como los criterios para establecer su distribución o intercambio. Hume rechaza la posibilidad de la distribución igualitaria de la propiedad ya que, en última instancia, esto eliminaría la competencia y haría desaparecer el incentivo para el trabajo, además de que sería imposible sin introducir mecanismos fuertemente coercitivos, por no decir que si distribuimos las posesiones de forma igualitaria lo que resultará es "que los diferentes grados de arte, cuidado e industria de los hombres, romperán inmediatamente esa igualdad" ${ }^{20}$. Lo que se necesitan son unas reglas de asignación lo más asépticas posibles. Es interesante el paralelismo que se establece entre los mecanismos mentales de la asociación de ideas y los criterios para la asignación, el intercambio y cesión de la propiedad, pues al echar mano a principios que rigen el funcionamiento de nuestra mente se pretende hacer más "natural" la estabilidad y distribución de la propiedad.

Está claro que intentar resumir en unas pocas páginas el pensamiento político de un autor de la grandeza y sutileza de Hume, y además pretender situarlo en unas hipotéticas coordenadas de la historiografía de las ideas políticas es, por decirlo caritativamente, un ejercicio de filosofía ficción. No obstante, a modo de cierre quisiera extraer las conclusiones de ese ejercicio, porque considero que arrojan luz no solo al momento de transición y de cambió hacia el orden capitalista que estaba ayudando a articular, sino también a nuestro momento actual.

Para Hume la política o la ciencia política es uno de los saberes que forman parte del proyecto general de ciencia de la naturaleza human. Como tal es un saber práctico, que tiene como objetivo incidir en las opiniones sobre lo político, i.e. sobre las relaciones de dependencia que resultan de la natural sociabilidad humana, para intentar transformarlas. Esta transformación debe partir de las condiciones particulares a las que la historia nos ha traído, el objetivo coyuntural, en el caso de Hume, será neutralizar la influencia de pasiones poco moderadas o negativas como pueden ser el miedo o el orgullo desmedido, que están en la base del fanatismo, en su época inoculado por las falsas religiones, superstición y entusiasmo.

Así pues, Hume es un realista político en un doble sentido: los mimbres con los que articula su proyecto general u orden social son, por una parte, las necesidades que obligan a los hombres a asociarse para subsistir, una asociación que no podría tener lugar si no se respetasen las normas de la equidad y la justicia, el incentivo para su respeto en primera instancia debiera ser un cierto

\footnotetext{
${ }^{20}$ Hume, D. 1991. Investigación sobre los principios de la moral. Madrid: Espasa Calpe. Edición y traducción de Gerardo López Sastre, Sec. 3, p. 67.
}

Araucaria. Revista Iberoamericana de Filosofia, Política, Humanidades y Relaciones Internacionales, año $20, \mathrm{n}^{\circ} 40$ Segundo semestre de 2018. Pp. 333-347. ISSN 1575-6823 e-ISSN 2340-2199 doi: 10.12795/araucaria.2018.i40.15 
cálculo racional al servicio del disfrute y el intercambio de las posesiones y el cumplimiento de las promesas, acuerdos y contratos, en última instancia, se trata de aspirar a valores como lo útil, lo estable, lo agradable y lo placentero. Las leyes y las instituciones que emergen son legítimas en la medida que protegen estos fines y respaldan estos valores. Pero, por otra parte, también es realista porque, en tanto que historiador, no plantea una teoría utópica ni una situación imaginaria o hipotética, no hay un borrón y cuenta nueva, nacemos en sociedades con gobiernos e instituciones políticas, la transformación debe hacerse desde dentro.

Ni conservador ni revolucionario, Hume abogaría por una transformación gradual en las prácticas puesto que ni tan siquiera ofrece una definición general de justicia, no hay esencialismo, hay pactos y acuerdos que deben ser respetados y deberes que emergen de las posiciones o roles que cada cual ocupa en la sociedad, del contrato implícito de lo que una persona es en relación a otras: hijo, profesor, gobernante, ciudadano, comerciante... que implican deberes y lealtades en relación a otras personas e instituciones, relaciones que son el marco o la oportunidad para el cultivo del resto de virtudes, algo que amplía el marco de la justicia de lo meramente distributivo.

Podemos plantearnos para finalizar cuál es el tipo de individuo y cuál es el tipo de sociedad que emerge del pensamiento político de Hume. Para contestar a la primera pregunta echaré mano de nuevo de Ernest Gellner, tomando prestada una de sus maravillosas imágenes. Como planteé al principio esta visión de la política cuyas bases son el libro III del Tratado, se sostiene en la concepción de la naturaleza humana que resulta de los dos libros anteriores, fundamentalmente del I, en el que Hume circunscribe el conocimiento a la experiencia. La insistencia en que el hombre conoce y se conoce a partir de las percepciones contribuye a que emerja una visión de la naturaleza humana totalmente naturalizada, Gellner lo bautiza como el bundleman, el hombre haz, un hombre cuyas ideas provienen de las impresiones y cuya moralidad estriba en un tipo de sentimiento que en última instancia favorece lo que es más conveniente colectivamente. Este bundleman es descrito con bastante sorna por el filósofo checo como una mezcla entre gourmet y contable con un toque de compasiva sensibilidad:

"He conducted his life by studying his palate and seeking to arrange for its greatest satisfaction, and his imaginative sympathy for others inclined him to favour their satisfactions too, if to a somewhat lesser degree than his own"21.

Egoísmo moderado, defensa de la propiedad, fidelidad a las promesas, pactos y contratos, con espíritu equitativo y confiado. El bundleman, la persona

\footnotetext{
${ }^{21}$ Gellner, E. (1985) The Psychoanalitic movement. The Cunning of Unreason. Northwestern University Press Evanston, Illinois, p.15.
}

Araucaria. Revista Iberoamericana de Filosofia, Politica, Humanidades y Relaciones Internacionales, año 20, $\mathrm{n}^{\circ} 40$. Segundo semestre de 2018. Pp. 333-347. ISSN 1575-6823 e-ISSN 2340-2199 doi: 10.12795/araucaria.2018.i40.15 
ideal para esa sociedad mercantil, liberal y burguesa que se concibe según palabras de Gerardo López Sastre como una "sociedad de propietarios", no una comunidad sino una societas ${ }^{22}$. Un pensamiento político, en suma, al servicio de un cambio social moderado de camino hacia el mundo capitalista moderno.

Pero si Hume es importante por articular una nueva manera de codificar las relaciones individuo y sociedad para la nueva sociedad emergente, la sociedad ideal de los bundleman, no lo es menos por describir el pays reel de las relaciones políticas humanas que tienen más que ver con las relaciones dialécticas entre entusiasmo y superstición. Ahí considero que es más realista que en lo primero.

${ }^{22}$ Lopéz Sastre, G. Hume. Cuándo saber ser escéptico. Ed. El país, Madrid, 2015. 


\section{Referencias bibliográficas:}

Gellner, E. (1985) The Psychoanalytic movement. The Cunning of Unreason. Northwestern University Press Evanston, Illinois.

Haakonssen, K.: “The structure of Hume's polítical theory" en Norton, D. F. (ed.) (1993): The Cambridge Companion to Hume. Cambridge, Cambridge University Press.

Hume, D, (1993): Dialogues and Natural History of Religion. Ed. J. C. A. Gaskin, Oxford, Oxford University Press.

Hume, D. (1977): Compendio de un tratado de la naturaleza humana. Versión castellana de Carmen García Trevijano y Antonio Garcia Artal. Valencia, Teorema.

Hume, D. (1987): Ensayos políticos, Madrid, Tecnos.

Hume, D. (1991) Investigación sobre los principios de la moral. Un dialógo, Edición y traducción de Gerardo López Sastre, Espasa-Calpe, Madrid.

Hume, D. (2004): Investigación sobre el entendimiento humano. Edición bilingüe. Traducción de Vicente Sanfélix Vidarte y Carmen Ors Marqués. Introducción, notas y comentarios de Vicente Sanfélix Vidarte. Epílogo de Barry Stroud, Madrid, Ediciones Istmo.

Hume, D. (2011): Ensayos morales, politicos y literarios. Edición, prólogo y notas de Eugene F. Miller. Traducción de Carlos Martín Ramírez. Madrid, Editorial Trotta y Liberty Fund.

Hume, D. (1988): Tratado de la naturaleza humana. Edición de Félix Duque. Madrid. Tecnos.

Nussbaum, M. C. (2015) La fragilidad del bien. Fortuna y ética en la tragedia y en la filosofía griega. Madrid, Antonio Machado Libros.Smichtt, C. (1999): El concepto de lo político. Alianza Editorial, Madrid. 
